\title{
Mycofumigation with the endophytic fungi Fusarium proliferatum (Matsushima) Nirenberg and Diaporthe sp. for the control of banana and mango anthracnose
}

\author{
Rochelle B. Cagadas' ${ }^{* 2}$ Flor A. Ceballo',Christian Joseph R. Cumagun' and \\ Ireneo B. Pangga'
}

Banana and mango are the top commodities in the Philippines that are traded worldwide however, fungal diseases such as anthracnose affect their yield and quality. Environmentally sound control strategies have been explored and one of these is mycofumigation using fungal endophytes. This alternative approach is understudied in the Philippines, hence, the study aimed to evaluate the mycofumigation potential of fungal endophytes collected from Mt. Makiling, Luzon, Philippines and their pathogenicity to banana and mango fruits. In vitro and in vivo mycofumigation assays were conducted with a completely randomized design layout with triplicates per treatment under laboratory conditions.

The fungal endophytes used as mycofumigants, Diaporthe sp. and Fusarium proliferatum, were comparatively effective in controlling the anthracnose of banana and mango. The mycelial growth for in vitro assay of Colletotrichum musae and Colletotrichum gloeosporioides were significantly reduced compared to the control when exposed to volatile organic compounds produced by the fungal endophytes. In addition, the results of the in vivo mycofumigation assay against $C$. musae showed Diaporthe $\mathrm{sp}$. had a significantly higher inhibition rate $(93 \%)$ than $F$. proliferatum $(67 \%)$ when grown on potato dextrose agar plates.

The bioefficacy of the Diaporthe sp. and F. proliferatum was improved when grown on peanut and corn seed substrates with a reduction of banana and mango anthracnose severity ranging from 82 to $100 \%$. Cultures grown on corn substrate performed better than those grown on peanut. Pathogenicity tests also revealed that these endophytic fungi did not cause disease in the banana

${ }^{1}$ Institute of Weed Science, Entomology and Plant Pathology, College of Agriculture and Food Science, ${ }^{2}$ University of the Philippines Los Baños, 4031 College, Laguna

*Corresponding Author. Address: PhilRootcrops, Visayas State University; Email: rbcagadas1@up.edu.ph 
or mango fruits indicating their potential as good biocontrol agents against $C$. musae and $C$. gloeosporioides.

Keywords: calcium nitrate, soil amendment, anthracnose, Rhizopus stolonifer, Dioscorea rotundata

\section{INTRODUCTION}

Banana (Musa spp.) and mango (Mangifera indica L.) are the leading agricultural commodities produced and traded in the Philippines. For exports, the Philippines ranked second (2019) in banana and seventh in mango (2015), with USD1.9 billion (13.2\%) and USD91 million (4\%) share of the global market, respectively (Workman 2019, UNComtrade 2016). Nevertheless, constant usage of synthetic fungicides is reported to have had carcinogenic impacts on agriculture workers, residual toxicity, ecological pollution, (Nicolopoulou-Stamati et al 2016) and the development of pathogen fungicide-resistance which was observed in Imazalil fungicides (AbdelRahim and Abo-Elyousr 2017).

The post-harvest quality of the banana and mango fruits are affected by disease-causing microorganisms such as Colletotrichum causing anthracnose which is the major pre- and post-harvest pathogen. It is successful as a post-harvest pathogen because of latent infections in which symptoms become apparent as the fruit ripens (Prusky 1996). Banana anthracnose caused by Colletotrichum musae (Berk. and M.A. Curtis) Arx results in 30-40\% losses of marketable fruit (Ranasinghe et al 2003). On the other hand, C. gloeosporioides (Penzig) Sacc that causes mango anthracnose results in 30-60\% yield losses of mango across different countries of the world (Chowdhury and Rahim 2009).

Hot water treatment and the application of synthetic fungicides such as benomyl, thiabendazole (TBZ), prochloraz, and imazalil are commonly practiced for controlling anthracnose diseases (Khan et al 2001, Nelson et al, Perdichizzi et al 2014, Mari et al 2007, Jinasena et al 2011). Nowadays, researchers are eager to discover alternative control measures that are economically viable and ecologically sound such as mycofumigation using endophytes. Mycofumigation is the use of volatile organic compounds (VOCs) produced by fungi to inhibit the growth of phytopathogenic fungi associated with post-harvest diseases. The mycofumigation is convenient since it has no direct contact between the antagonist and the plant product, easily diffuses in closed environments with no residues remaining on the plant product to be consumed. In addition, most of the antimicrobial volatile mixtures exhibit bioactivity against a wide range of microorganisms, including many phytopathogens associated with post-harvest diseases (Gomes et al 2015). Endophytes are any organisms (bacteria or fungi) present inside plant tissues that do not cause visible disease in the plant but show mutualistic, parasitic, and commensalistic relationship with the host through protecting plants against herbivores, insect attacks, or tissue invading pathogens (Singh et al 2011). They have been known as prominent sources of new bioactive constituents such as alkaloids, terpenoids, steroids, quinones, isocoumarins, lignans, phenols, and lactones (Yu et al 2010). For instance, various valuable bioactive compounds with antimicrobial, insecticidal, cytotoxic, and anticancer activities were discovered from endophytic fungi which have potential as mycofumigants (Zhao et al 2011). 
Adiova (2019) isolated three promising endophytic fungi - Tinctoporellus epimiltinus, Fusarium proliferatum (Matsushima) Nirenberg and Diaporthe sp. from plants in Mt. Makiling, Luzon, Philippines, namely Arcangelisia flava (L.) Merr, Macaranga grandifolia (L.) and Tetrastigma harmandii Planch., that were effective in suppressing the growth of $C$. musae in vitro and in vivo. The antifungal property was due to the release of volatile compounds such as phenylethyl alcohol, beta-acorenol and acoradiene from F. proliferatum; 2-tridecanon and 1-decanol from Diaporthe sp. Few studies have been done to verify the mycofumigation potential of these fungal endophytes. Thus, the study aims to: (1) evaluate the effectivity of the endophytic fungi $F$. proliferatum and Diaporthe $\mathrm{sp}$. in controlling banana and mango anthracnose (in vitro and in vivo), (2) assess the effect of seed substrates on the virulence of endophytic fungi, (3) test the pathogenicity of the endophytic fungi to banana and mango fruits.

\section{MATERIALS AND METHODS}

\section{Isolation, Identification, and Maintenance of C. musae and C. gloeosporioides}

C. musae and C. gloeosporioides were isolated from banana and mango fruits showing typical anthracnose symptoms. Tissue sections were excised from the advancing margin of a lesion including both diseased and healthy parts. The cut sections were surfaced sterilized by dipping in $10 \%$ sodium hypoclorite $(\mathrm{NaOCl})$ (Critzer et al 2012) for 3min and rinsed three times in sterile distilled water. Tissue sections were blot dried on sterile filter paper and transferred equidistant onto potato dextrose agar (PDA) plates. After 3 days, when actively growing cells were present and suitable for isolation, the advancing mycelial growth was transferred to PDA slants and plates.

\section{Mass Production of Endophytic Fungi}

Endophytic fungi were obtained from the original pure cultures used by Adiova (2019) who isolated Diaporthe sp. and F. proliferatum from the stems of Tetrastigram harmandii, and Macanga grandifolia, respectively, which were collected from Mt. Makiling. The revived endophytic fungal isolates were maintained on potato dextrose agar (PDA) plates and incubated at room temperature.

\section{In Vitro Mycofumigation Assay}

The ability of the endophytic fungi to inhibit the growth of $C$. musae and $C$. gloeosporioides through the production of VOCs was tested using double-plate assay adopted from Reddy et al (2007) with minor modifications. The bottom plate of the freshly planted mycelial disc of the test pathogen was joined with the bottom plate of the 5-day-old culture of each endophytic fungi and sealed with tape. The control treatment was the test pathogen alone. The set-up was replicated three times per treatment and incubated until the growth of the control treatments covered the petri plate at the optimum of 7 days incubation. Daily measuring of the diameter of the pathogen was done as the average of two diameters for each replicate. 
Percentage inhibition was determined following the formula:

$$
\text { Percentage inhibition }=\frac{D_{c}-D_{t}}{D_{c}} \times 100
$$

where:

$$
\begin{aligned}
& D_{c}=\text { diameter of test pathogen in control treatment } \\
& D_{t}=\text { diameter of test pathogen with endophyte }
\end{aligned}
$$

\section{In Vivo Mycofumigation Assay}

Using a micropippete, eight microliters from the adjusted conidial suspensions $\left(10^{6}\right.$ conidia per $\mathrm{mL}$ ) of C. musae were inoculated into wounded banana fruits (Adiova 2019) by dropping the inoculum into the wounded peel surfaces at 3 wounds per fruit. The wounding was done by pricking the fruit surfaces to a depth of approximately one half of the peel's thickness. After which, two fruits were placed separately into sterile polypropylene bags with five plates of 5-day-old cultures of endophytic fungi. The control treatments were uninoculated and inoculated with the test pathogen. The setup had triplicates per treatment and layout in a Completely Randomised Design (CRD). Lesion size per wound was determined and percentage inhibition was computed.

\section{In Vivo Effect of Substrates on the Virulence of Promising Endophytic Fungi}

Peanut, rice, and corn seeds were used as substrates for the two endophytic fungi as an alternative media to PDA for mass production. The fungi grown on these substrates were evaluated for the bioefficacy of their performance in controlling the anthacnose in vivo. The seed substrates were boiled for 10-15min. Each medium, weighing $40 \mathrm{~g}$ was placed into Petri plates and autoclaved twice at $121^{\circ} \mathrm{C}$ for $30 \mathrm{~min}$. After cooling, each Petri plate with a substrate was inoculated with a mycelial disc $(\sim 5 \mathrm{~mm})$ of 5-day-old pure culture of the endophytic fungi. The fungal cultures were incubated until covering $70-90 \%$ of the plates prior to doing the same in vivo mycofumigation assay as previously described.

\section{Pathogenicity Test of Endophytic Fungi in Banana and Mango Fruits}

Surface sterilized unripe banana and mango fruits were used for the pathogenicity test of Diaporthe sp. and F. proliferatum. Mycelial agar discs $(\sim 5 \mathrm{~mm})$ from the periphery of 5-day-old cultures of $F$. proliferatum and Diaporthe sp. were placed on wounded and unwounded tissues. The fruits were incubated in polypropylene bags lined with moist tissue paper for $48 \mathrm{~h}$. Observation was done for 7 days after inoculation.

\section{Data Analysis}

All data from the experiments except for the pathogenicity test were subjected to Analysis of Variance (ANOVA) and means were compared by Tukey's Honest Significant Difference (HSD) test. 


\section{RESULTS AND DISCUSSION}

\section{In Vitro Mycofumigation Assay}

The study assessed the antagonistic property of the two endophytic fungi against $C$. musae and $C$. gloeosporioides through double plate assay. The VOCs of the endophytic fungi had significant antimicrobial effect on the $C$. gloeosporioides and $C$. musae compared to the control. The endophytic fungi, namely F. proliferatum and Diaporthe sp. reduced the mycelial growth of $C$. gloeosporioides and $C$. musae. C. musae exposed to VOCs of $F$. proliferatum had smaller colony growth $(74 \mathrm{~mm})$ than Diaporthe sp. $(80 \mathrm{~mm})$ (Table 1). Nevertheless, F. proliferatum had comparable inhibition rate (16\%) as compared with Diaporthe sp. (10\%) against $C$. musae.

Table 1. Effect of volatile organic compounds of Diaporthe sp. and F. proliferatum on the colony growth of $C$. musae and $C$. gloeosporioides

\begin{tabular}{|c|c|c|c|c|}
\hline \multirow{2}{*}{ Treatments } & \multicolumn{2}{|c|}{ Colony growth $(\mathrm{mm})$} & \multicolumn{2}{|c|}{ Percent inhibition } \\
\hline & C. musae & C. gloeosporioides & C. musae & C. gloeosporioides \\
\hline Pathogen alone & $89.0^{b}$ & $63.0^{a}$ & $0.0^{\mathrm{a}}$ & $0.0^{\mathrm{a}}$ \\
\hline Co-cultured with & & & & \\
\hline Diaporthe sp. & $80.0^{a b}$ & $52.0^{\mathrm{a}}$ & $10.0^{b}$ & $17.0^{b}$ \\
\hline Co-cultured with $F$. & & & & \\
\hline proliferatum & $74.0^{\mathrm{a}}$ & $49.0^{\mathrm{a}}$ & $16.0^{\mathrm{b}}$ & $22.0^{\mathrm{b}}$ \\
\hline $\operatorname{Pr}(>F)$ & 0.0298 & 0.0298 & 0.7462 & 0.8775 \\
\hline
\end{tabular}

Means followed by the same letter are not significantly different at $a=0.05$

On the other hand, the mean colony growths of $C$. gloeosporioides sub-cultured with the two fungal endophytes were similar with the control (Table 2). F. proliferatum showed a higher inhibition rate $(22 \%)$ on the growth of $C$. gloeosporioides than Diaporthe sp. (17\%). Although Diaporthe sp. and F. proliferatum inhibited the growth of $C$. gloeosporioides, there were no significant differences in the mean percent inhibition between the two treatments. According to Cumagun et al (2019), the volatile compounds that possibly inhibit the growth of the $C$. musae were phenylethyl alcohol, beta-acorenol and acoradiene in F. proliferatum and 2-tridecanon and 1decanol in Diaporthe sp. The study was also in consonance with Strobel et al (2001) in which the VOCs produced by the endophytic fungus, Muscodor albus inhibited the germination of the teliospores of Tilletia horrida, T. indica, and T. tritici (pathogenic fungi that cause the plant diseases rice kernel smut, wheat kernel bunt and wheat common bunt, respectively). The VOC molecules produced from M. albus were 1butanol and 3-methyl-acetate that reduced the growth of Cercospora beticola, Fusarium solani, Pythium ultimum, Rhizoctonia solani, Sclerotinia sclerotiorum, Tapesia yallundae, and Xylaria sp.

\section{In Vivo Mycofumigation Assay}

Seven days after inoculation, the two endophytic fungi significantly reduced the anthracnose disease severity in banana fruits compared to the control. Diaporthe sp. (Table 3) showed a better performance, with a mean lesion size of $14 \mathrm{~mm}^{2}$ and 
inhibition of $93 \%$, compared with $F$. proliferatum with $74 \mathrm{~mm}^{2}$ lesion size and $67 \%$ inhibition. The inhibiton may be due to the presence of the VOCs identified by Cumagun et al (2019), which reduced the progression of anthracnose in the banana fruits. The VOCs may affect the sporulation of the pathogen that inhibited the occurrence of the disease. Reports stated by Gao et al (2017) that the VOC, 2tetradecanone from endophyte strain ZSY-1, affected the spore synthesis system of Alternaria solani and has the potential for controlling tomato grey mold and early blight.

Table 2. Severity of anthracnose in wound-inoculated banana fruits exposed to volatile organic compounds of endophytic fungi, 7 DAI

\begin{tabular}{lcc}
\hline Treatments & Lesion size $\left(\mathrm{mm}^{2}{ }^{2}\right)$ & Percent inhibition \\
\hline Uninoculated control & $0.0^{\mathrm{a}}$ & $0.0^{\mathrm{c}}$ \\
Inoculated control & $266.0^{\mathrm{c}}$ & $0.0^{\mathrm{c}}$ \\
Diaporthe sp. & $14.0^{\mathrm{a}}$ & $93.0^{\mathrm{a}}$ \\
F. proliferatum & $74.0^{\mathrm{b}}$ & $67.0^{\mathrm{b}}$ \\
$\operatorname{Pr}(>\mathrm{F})$ & $<0.0001$ & $<0.0001$ \\
\hline
\end{tabular}

Means followed by the same letter are not significantly different at $a=0.05$

Similar results were also observed by Adiova (2019) that endophytic fungi, namely Diaporthe sp. and F. proliferatum including Tinctoporellus epimiltinus, suppressed the development of $C$. musae on artificially inoculated banana fruits. On the other hand, other endophytic fungi such as $F$. oxysporum, $F$. proliferatum, Lasiodiplodia sp., and L. theobromae, showed activities against yeasts while Xylaria sp., F. oxysporum, Colletotrichum. tropicale, F. proliferatum, Colletotrichum siamense inhibited gram-negative bacteria. Differences in cell wall composition may also explain this group-directed activity but this requires further testing of their mechanism of action (Moron et al 2018).

\section{In Vivo Effect of Substrates on the Virulence of Promising Endophytic Fungi}

Promising endophytic fungi namely Diaporthe sp. and F. proliferatum as mycofumigants were grown on low cost substrates like seeds to improve biological efficacy. Screening for proper substrate is important since fungal growth and production of VOCs are greatly influenced by the composition of the growth substrates. According to Jackson and Schisler (1992), the C:N ratio not only affects the mycelial and spore production, but also affects the biocontrol efficacy as it also impacts production of various secondary metabolites.

In this study, Diaporthe sp. and F. proliferatum were grown on rice, corn, and peanut seeds as solid substrates for the mycofumigation assay. Differences in growth responses of $F$. proliferatum and Diaporthe sp. were observed for each substrate. Peanut and corn substrates were colonized by $F$. proliferatum and Diaporthe sp. at a faster rate which took 8 days to attain the $70-90 \%$ colonization of substrates on Petri plates but the growth rate of the endophytic fungi on rice substrates was slower than corn and peanut substrates. F. proliferatum exhibited faster growth across different substrates $(62 \mathrm{~mm}, 46 \mathrm{~mm}$, and $55 \mathrm{~mm})$ than Diaporthe sp. ( $59 \mathrm{~mm}, 18 \mathrm{~mm}$, and $53 \mathrm{~mm})$ for corn, rice, and peanut eight days after inoculation, respectively. 
The colony growth of endophytic fungi was influenced by the type of substrate used. Diaporthe sp. and $F$. proliferatum were best grown on corn substrate with mean colony growths of $59 \mathrm{~mm}$ and $62 \mathrm{~mm}$, respectively (Table 3 ). It was followed by peanut with mean colony growths of $53 \mathrm{~mm}$ and $55 \mathrm{~mm}$ and lastly, rice seeds with mean colony growths of $18 \mathrm{~mm}$ and $46 \mathrm{~mm}$, respectively. Ezra and Strobel (2003) stated that high levels of a carbon source in the growing medium results in a higher number of VOCs emitted by Muscudor albus with dramatic consequences on the ability of the fungus to inhibit or kill the pathogenic fungi. Rice as a substrate was excluded from the succeeding assays because it lacked the requirements for the optimum growth and development of the endophytic fungi due to the low moisture content of the rice grain after sterilization and the thickness of the hull.

Table 3. Growth of Diaporthe sp. and F. proliferatum on peanut, rice, and corn substrates 8 days after inoculation.

\begin{tabular}{ccc}
\hline Substrate & Endophytic fungus & Colony growth $(\sim \mathrm{mm})$ \\
\hline Peanut & Diaporthe sp. & $53.0^{\mathrm{a}}$ \\
& F. proliferatum & $55.0^{\mathrm{a}}$ \\
Rice & Diaporthe sp. & $18.0^{\mathrm{b}}$ \\
& F. proliferatum & $46.0^{\mathrm{b}}$ \\
Corn & Diaporthe sp. & $59.0^{\mathrm{a}}$ \\
& F. proliferatum & $62.0^{\mathrm{a}}$ \\
\hline $\operatorname{Pr}(>\mathrm{F})$ & $<.0001$ & $\operatorname{Pr}(>\mathrm{F})$ \\
\hline
\end{tabular}

Means followed by the same letter are not significantly different at $a=0.05$

The mycofumigant potential of the endophytic fungi against banana and mango anthracnose was increased when they were grown on corn and peanut substrates. In the in vivo assay, the growth of $C$. musae was severely suppressed 7 days after inoculation when exposed to Diaporthe sp. and $F$. proliferatum grown on corn and peanut substrates and significantly different from the control (Table 4). The endophytic fungi showed higher efficacy when grown on corn substrates than peanut substrates even though there was no significant difference in terms of suppression of the pathogen. No anthracnose symptom was observed when exposed to the endophytic fungi grown on corn substrates while slow anthracnose progression was observed in the banana fruits exposed to the endophytic fungi grown on peanut substrates. The reduction of lesion size by the VOCs of Diaporthe $\mathrm{sp}$. was comparable to $F$. proliferatum. The inhibition rate of both endophytic fungi ranged from $80-100 \%$.

On the other hand, the two endophytic fungi showed a comparable effect in reducing pathogen inoculated mango anthracnose disease severity compared to the inoculated control mango fruits (Table 4). The uninoculated control did not exhibit observable anthracnose symptoms (Figure 1). Nine days after inoculation, mango fruits inoculated with $C$. gloeosporioides being exposed to VOCs of Diaporthe sp. showed the highest growth inhibition (100\%) followed by the inoculated fruits of $C$. gloeosporioides that were exposed to F. proliferatum (98\%). Although the means of percent inhibition of samples varied, the effects were statistically not significantly different between the two endophytic fungi (Figure 1). 
Table 4. Severity of anthracnose in wound-inoculated banana fruits exposed to volatile organic compounds of endophytic fungi grown in corn and peanut substrates

\begin{tabular}{|c|c|c|c|c|}
\hline \multirow{2}{*}{ Treatments } & \multicolumn{2}{|c|}{ Lesionsize $\left(\mathrm{mm} \quad{ }^{2}\right)$} & \multicolumn{2}{|c|}{ Percentinhibition } \\
\hline & banana & mango & banana & mango \\
\hline Uninoculated control & $0.0^{a}$ & $0.0^{\mathrm{a}}$ & $0.0^{b}$ & $0.0^{b}$ \\
\hline $\begin{array}{l}\text { Inoculated control } \\
\text { Com }\end{array}$ & $287.0^{c}$ & $336.0^{b}$ & $0.0^{b}$ & $0.0^{b}$ \\
\hline Diaporthe sp. & $0.0^{a}$ & $0.0^{\mathrm{a}}$ & $100.0^{a}$ & $100.0^{a}$ \\
\hline $\begin{array}{l}\text { F.proliferatum } \\
\text { Peanut }\end{array}$ & $0.0^{a}$ & $0.0^{\mathrm{a}}$ & $100.0^{a}$ & $100.0^{a}$ \\
\hline Diaporthe sp. & $0.0^{a}$ & $0.0^{\mathrm{a}}$ & $100.0^{a}$ & $100.0^{a}$ \\
\hline F. proliferatum & $48.0^{b}$ & $3.0^{\mathrm{a}}$ & $83.0^{a}$ & $98.1^{\mathrm{a}}$ \\
\hline $\mathrm{P}(>\mathrm{F})$ & 0.0001 & $<.0001$ & $<0.0001$ & 0.0003 \\
\hline
\end{tabular}

Means followed by the same letter are not significantly different at $\mathrm{a}=0.05$

C.musae and C. gloeosporioides that were isolated from the treated banana and mango that showed no progression of symtoms during the experiment were recovered when plated on PDA which indicated that the endophytic fungi exhibited a fungistatic mode of action. The VOCs of endophytic fungi did not kill the pathogen instead they only reduced the virulence of the pathogen resulting in no visible anthracnose symptoms.

The results also conformed with Cumagun et al (2019) demonstrating the significant growth reduction of $C$. musae by Diaporthe sp. and $F$. proliferatum during in vivo evaluation and no significant differences on the performance of both endophytic fungi regardless of media used. Mercier and Jimenez (2004) believed that the production cost of $M$. albus as a biological control agent in agricultural applications was low and could be cultivated on readily available substrates such as rye grain. $M$. albus growing on autoclaved rye produces 2-methyl-1-butanol $(48.5 \%)$ as the major component in the headspace along with isobutyric acid $(14.9 \%)$ and ethyl propionate (9.63\%) as the second and third major components, respectively. The mechanism of the growth inhibition by the endophytic fungi VOCs may be the alteration of the respiration and the cell permeability of the pathogen. For example, Fusarium oxysporum's growth and respiration was inhibited by endophytes' VOCs through cell membrane damage (Macías-Rubalcava et al 2018).

\section{Pathogenicity Test of Endophytic Fungi}

After seven days of incubation, necrotic lesions were observed on the inoculation site of banana and mango for Diaporthe sp. and F. proliferatum, but the lesions did not progress indicating that the promising endophytic fungi were not pathogenic. The pathogenicity test suggested that $F$. proliferatum and Diaporthe sp. were promising biocontrol agents against $C$. musae and $C$. gloeosporioides and safe to apply as mycofumigants without any harmful effect to postharvest banana and mango fruits. 

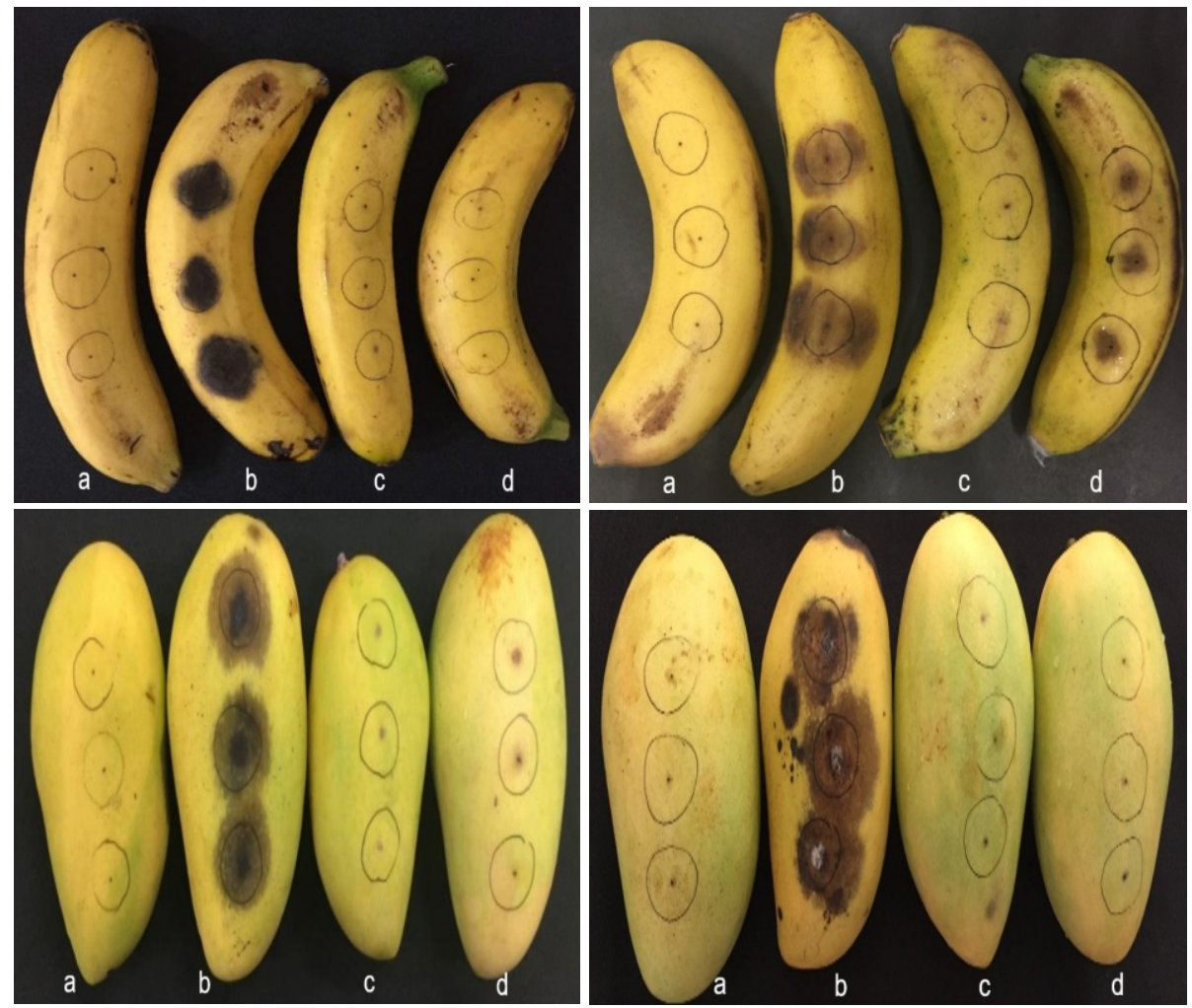

Figure 1. Severity of anthracnose on banana and mango fruits wound-inoculated with Colletotrichum musae (top) and Colletotrichum gloeosporioides (bottom) when exposed to volatile organic compounds (VOCs) of Diaporthe sp. and F. proliferatum which were grown in corn (left) and peanut (right) substrates. a. uninoculated control, b. inoculated control, c. Diaporthe sp., d. F. proliferatum

\section{CONCLUSION}

Mycofumigation using endophytic fungi is an efficient technique to reduce the anthracnose severity of banana and mango. In vivo mycofumigation assay using corn and peanut substrates increased the bioeffecacy of the endophytic fungi against the anthracnose that ranged from 80 to $100 \%$ inhibition. In addition, $C$. musae and C. gloeosporioides were recovered when plated on PDA which indicated that endophytic fungi exhibited a fungistatic mode of action. On the other hand, the pathogenicity test revealed that the endophytic fungi did not cause visible diseasein banana and mango fruits indicating Diaporthe sp. and F. proliferatum can be used as effective mycofumigants against $C$. musae and $C$. gloeosporioides.

\section{ACKNOWLEDGMENT}

We thank the Department of Science and Technology-Accelerated Science and Technology Human Resource Development Program-National Science Consortium 
(DOST-ASTHRDP-NSC) for funding the research, Sir Adiova for providing the endophytic fungi isolates and University of the Philippines, Los Baños, College of Agriculture and Food Science, Institute of Weed Science, Entomology and Plant Pathology (UPLB-Los Baños, CAFS, IWEP) for acquisition of other plant pathogens.

\section{REFERENCES}

Abdel-Rahim I and Abo-Elyousr KAM. 2017. Using of endophytic Saccharomycopsis fibuligera and thyme oil for management of gray mold rot of guava fruit. Biological Control 110:124-131

Adiova J. 2019. Screening, identification and evaluation of fungal endophytes from Mount Makiling as mycofumigant against Colletotrichum musae (Berk. and M.A. Curtis) Arx, causal organism of banana anthracnose. (Unpublished PhD dissertation). University of the Philippines, Los Baños, Laguna, Philippines

Bennett $\mathrm{J}$ and Inamdar A. 2015. Are some fungal volatile organic compounds (VOCs) mycotoxins?. Toxins 7(9):3785-3804

Chithra S, Jasim B, Mathew J \& Radhak-rishnan EK. 2017. Endophytic Phomopsis sp. colonization in Oryza sativa was found to result in plant growth promotion and piperine production. Physiologia Plantarum 160(4):437-446

Chowdhury MNA and Rahim MA. 2009. Integrated crop management to control anthracnose (Colletotrichum gloeosporioides) of mango. Journal of Agriculture and Rural Development 7(1):115-120

Critzer F, Wszelaki A \& Ducharme D. 2012. How to use and monitor chlorine (sodium/calcium hypochlorite) in fruit and vegetable washwater and on equipment and food contact surfaces. https://extension.tennessee.edu/publ ications/documents/SP798-A.pdf

Cumagun CJ, Lenz K, Jakobs R, Muller C, Rathgeb A \& Karlovsky P. 2019. Metabolic profiling of endophytic fungi acting as antagonists of the banana pathogen Colletotrichum musae. Poster in Institute of Weed Science, Entomology and Plant Pathology, UP Los Baños

Dame ZT, Silima B, Gryzenhout M \& Van Ree T. 2016. Bioactive compounds from the endophytic fungus Fusarium proliferatum. Natural Product Research 30(11):1301-1304

Ezra D and Strobel G. 2003. Substrate affects the bioactivity of volatile antimicro bials emitted by Muscodor albus. Plant Science 165:1229-1238

Gao Z, Zhang B, Liu H, Han J \& Zhang Y. 2017. Identification of endophytic Bacillus velezensis ZSY-1 strain and antifungal activity of its volatile compounds against Alternaria solani and Botrytis cinerea. Biological Control 105:27-39

Gomes AAM, Queiroz MV \& Pereira OL. 2015. Mycofumigation for the biological control of post-harvest diseases in fruits and vegetables: a review. Austin Journal of Biotechnology and Bioengineering 2(4):1-8

Hardoim PR, Van Overbeek LS, Berg G, Pirttilä AM, Compant S, Campisano A, Döring M \& Sessitsch A. 2015. The hidden world within plants: ecological and evolutionary consi-derations for defining functioning of microbial endophytes. Microbiology and Molecular Biology Reviews 79(3):293-320

Jalander V and Gachande BD. 2011. Effect of culture filtrates of Fusarium oxysporum on seed germination and seedl-ing growth of pigeonpea (Cajanus cajan) varieties. Bioscience Discovery 2(2):185-188 
Jackson MA and Schisler DA. 1992. The composition and attributes of Colletotrichum truncatum spores are altered by the nutritionalvenvironment. Applied and Environmental Microbiology 58(7):2260-2265

Jinasena D, Pathirathna P, Wickramarachchi S \& Marasinghe E. 2011. Use of chitosan to control anthracnose on "Embul" banana. International Conference on Asia Agriculture and Animal. IACSIT Press, Singapore

Khan SH, Aked J \& Magan N. 2001. Control of the anthracnose pathogen of banana (Colletotrichum musae) using antioxidants alone and in combination with thiabendazole or imazalil. Plant Pathology 50(5):601-608

Macías-Rubalcava ML, Sánchez-Fernández RE, Roque-Flores G, Lappe-Oliveras P \& Medina-Romero YM. 2018. Volatile organic compounds from Hypoxylon anthochroum endophytic strains as post- harvest mycofumigation alternative for cherry tomatoes. Food Microbiology 76:363-373

Mari M, Torres R, Casalini L, Lamarca N, Mandrin JF, Lichou J, Larena I, De Cal MA, Melgarejo P \& Usall J. 2007. Control of post-harvest brown rot on nectarine by Epicoccum nigrum and physico-chemical treatments. Journal of the Science of Food and Agriculture 87(7):1271-1277

Mercier $\mathrm{J}$ and Jiméne JI. 2004. Control of fungal decay of apples and peaches by the biofumigant fungus Muscodor albus. Postharvest Biology and Technology 31(1):1-8

Moron LS, Lim YW \& Dela Cruz TEE. 2018. Antimicrobial activities of crude culture extracts from mangrove fungal endophytes collected in Luzon Island, Philippines. Philippine Science Letters 11(Supplement): 28-36

Nelson SC, Ploetz RC \& Kepler AK. 2006. Species profiles for pacific island agroforestry: Musa species (banana and plantain). Musaceae (banana family). http://www.agroforestry.net/tti/Musa-banana-plantain.pdf

Nicolopoulou-Stamati P, Maipas S, Kotampasi C, Stamatis P \& Hens L. 2016. Chemical pesticides and human health: the urgent need for a new concept in agriculture. Frontiers in Public Health 4:1-8

Pant R. 2011. Seed mycoflora of coriander and effect of some fungal metabolite on seed germination and seedling growth. Asian Journal of Experimental Biological Sciences 2(1):127-130

Perdichizzi S, Mascolo MG, Silingardi P, Morandi E, Rotondo F, Guerrini A, Prete L, Vaccari M \& Colacci A. 2014. Cancer-related genes transcriptionally induced by the fungicide penconazole. Toxicology in Vitro 28(1):125-130

Photita W, Lumyong S, Lumyong P, Mckenzie EHC \& Hyde KD. 2004. Are some endophytes of Musa acumi-nata latent pathogens?. Fungal Diversity 16:131-140

Prusky D. 1996. Pathogen quiescence in postharvest diseases. Annual Review of Phytopathology 34:413-434

Promputtha I, Hyde KD, Mckenzie EH, Peberdy JF \& Lumyong S. 2010. Can leaf degrading enzymes provide evidence that endophytic fungi becoming saprobes?. Fungal Diversity 41(1):89-99

Ranasinghe L, Jayawardena B \& Abeywickrama K. 2005. An integrated strategy to control post-harvest decay of embul banana by combining essential oils with modified atmosphere packag-ing. International Journal of Food Science and Technology 40(1):97-103

Reddy KRN, Choudary KA \& Reddy MS. 2007. Antifungal metabolites of Pseudomonas fluorescens isolated from rhizosphere of rice crop. Journal of Mycology and Plant Pathology 37(2):1-5 
Rodriguez RJ, White JR JF, Arnold AE \& Redman RS. 2009. Fungal endophytes: diversity and functional roles. New Phytology 182(2):314-330

Siji S and Nandini PV. 2017. Chemical and nutrient composition of selected banana varieties of Kerala. International Journal of Advanced Engineering, Management and Science 3(4):401-404

Spalding DH. 1982. Resistance of mango pathogens to fungicides used to control postharvest diseases. Plant Disease 66(12):1185-1186

Strobel GA, Dirkse E, Sears J \& Markworth C. 2001. Volatile antimicrobials from Muscodor albus a novel endophytic fungus. Microbiology 147(11):2943-2950

Sturz AV, Christie BR \& Nowak J. 2000. Bacterial endophytes: potential role in developing sustainable systems of crop production. Critical Reviews in Plant Sciences 19(1):1-30

Subramanian D. 1969. Enzymes in pathogenesis. Proceedings of the Indian Academy of Sciences-Section B 69:133-141

Suryanarayanan TS, Thirunavukkarasu N, Govindarajulu MB \& Gopalan V. 2012. Fungal endophytes: an untapped source of biocatalysts. Fungal Diversity 54:19-30

UN Comtrade. 2016. World Mango Exports by All Reporters and Partners, 20052015 (based on Hs80540). United Nations Statistics Division (UNSD)

Verma VC, Kharwar RN \& Strobel GA. 2009. Chemical and functional diversity of natural products from plant associated endophytic fungi. Natural Product Communications 4(11):1511-1532

Vilaplana R, Hurtado G \& Valencia-Chamorro S. 2018. Hot water dips elicit disease resistance against anthracnose caused by Colletotrichum musae in organic bananas (Musa acuminata). Lebensmittel-Wissenschaft \& Technologie (LWT) 95:247-254

Vladimir ES, Martine B, Regine V \& Pattat NH. 1998. Processing of the pectate lyase Pell by extracellular protease of Erwinia chrysanthemi 3937. Molecular Microbiology 29(6):1459-1468

Workman D. 2019. Bananas Exports by Country. http://www.worldstopexports. com/bananas-exports-country/

Yu H, Zhang L, Li L, Zheng C, Guo L, LI W, Sun P \& Qin L. 2010. Recent developments and future prospects of antimicrobial metabolites produced by endophytes. Microbiological Research 165(6):437-449

Zhao J, Mou Y, Shan T, Li Y, Zhou L, Wang M \& Wang J. 2010. Antimicrobial metabolites from the endophytic fungus Pichia guilliermondii isolated from Paris polyphylla var. yunnanen-sis. Molecules 15(11):7961-7970

Zou WX, Meng JC, Lu H, Chen GX, Shi GX, Zhang TY \& Tan RX. 2000. Meta-bolites of Colletotrichum gloeos-porioides, an endophytic fungus in Artemisia mongo-lica. Journal of Natural Products 63(11):1529-1530 